JOURNAL OF NURSING PRACTICE AND EDUCATION

VOL. 01 NO. 02, JUNI 2021

DOI: $10.34305 /$ jnpe.v1i2.265
Ciptaan disebarluaskan di bawah Lisensi Creative Commons Atribusi-

NonKomersial-BerbagiSerupa 4.0

Internasional.

\title{
HUBUNGAN ANTARA KARAKTERISTIK IBU HAMIL DENGAN TINGKAT PENGETAHUAN TENTANG MANAJEMEN LAKTASI DI WILAYAH KERJA UPTD PUSKESMAS PASAWAHAN KABUPATEN KUNINGAN
}

\author{
Nurdewi Sulymbona, Evi Soviyati, Anggit Kartikasari, Nurrukmini Hamsah \\ STIKes Kuningan \\ nurdewi63@gmail.com
}

\begin{abstract}
Abstrak
Manajemen laktasi adalah suatu tatalaksana yang diperlukan untuk menunjang keberhasilan dalam proses menyusui. Manajemen laktasi bila tidak terlaksana dengan baik maka akan berdampak penurunan pemberian ASI dan bisa berdampak pada meningkatnya angka gizi buruk dan gizi kurang yang sehingga beresiko pada peningkatan angka kematian bayi.

Metode menggunakan analitic dengan rancangan cross sectional. Populasi pada penelitian ini yaitu seluruh ibu hamil di Wilayah Kerja UPTD Puskesmas Pasawahan dengan jumlah 346 ibu hamil menjadi 185 ibu hamil dengan secara Stratified Random Sampling. Penelitian ini menggunakan kuesioner.

Hasil penelitian ini bahwa tidak terdapat hubungan antara umur ibu hamil dengan tingkat pengetahuan tentang manajemen laktasi $(\mathrm{p}=0,199)$, tidak terdapat hubungan antara pendidikan ibu hamil dengan tingkat pengetahuan tentang manajemen laktasi $(p=0,064)$, tidak terdapat hubungan pekerjaan ibu hamil dengan tingkat pengetahuan tentang manajemen laktasi $(p=0,285)$, dan terdapat hubungan antara paritas ibu hamil dengan tingkat pengetahuan tentang manajemen laktasi $(\mathrm{p}=0,008)$ dan tingkat pengetahuan tentang manajemen laktasi.
\end{abstract}

Kata Kunci $\quad$ : Manajemen Laktasi, Karakteristik.

\section{Pendahuluan}

Manajemen Laktasi adalah upaya yang dilakukan untuk membantu ibu mencapai keberhasilan dalam menyusui bayinya. Bila manajemen laktasi tidak terlaksana dengan baik maka akan 
JOURNAL OF NURSING PRACTICE AND EDUCATION

VOL. 01 NO. 02, JUNI 2021

DOI: $\underline{10.34305 / J N P E . V 1 I 2.265}$
Ciptaan disebarluaskan di bawah

$\underline{\text { Lisensi Creative Commons Atribusi- }}$

NonKomersial-BerbagiSerupa 4.0

Internasional. berdampak penurunan pemberian ASI sehingga berdampak pada peningkatan angka gizi buruk dan gizi kurang yang beresiko pada peningkatan angka kematian bayi (Prasetyono \& Hani'ah, 2009).

Laktasi adalah keseluruhan proses dari menyusui mulai ASI diproduksi sampai proses bayi menghisap dan menelan ASI (Bidan Indonesia, 2018). Air Susu Ibu (ASI) merupakan gizi terbaik untuk bayi terutama dikhususkan untuk bayi yang berumur kurang dari enam bulan dianjurkan agar diberikan ASI eksklusif. selama 6 bulan. ASI eksklusif diberikan selama enam bulan pertama dan pemberian sampai umur anak 2 tahun, hal telah dibuktikan oleh peneliti bahawa dapat mencegah penyakit-penyakit seperti kanker anak, pneumonia, diare, kegemukan, diabetes, penyakit jantung dan pembuluh darah, alergi, dan asma. Pemberian ASI eksklusif dimulai sejak lahir sampai umur 6 bulan, baru kemudian diperkenalkan dengan makanan padat (Tarigan \& Aryastami, 2012).

Berdasarkan data Unicef (2015), sebanyak 136,7 juta bayi lahir di seluruh dunia dan hanya $32,6 \%$ disusui secara eksklusif selama 6 bulan. Bayi yang tidak diberi ASI Eksklusif di negara industri lebih besar meninggal dari pada bayi yang diberi ASI Eksklusif, sementara di negara berkembang hanya berkisar 39\% ibu-ibu yang memberikan ASI Eksklusif untuk bayinya. WHO (2013) mengatakan angka pemberian ASI eksklusif di dunia berkisar $38 \%$ jika dibandingkan dengan target WHO mencapai 50\%, maka angka tersebut masih sangat jauh dari target yang diharapkan. Pencapaian ASI Eksklusif di Indonesia belum mencapai $80 \%$, secara nasional cakupan pemberian ASI eksklusif sebesar $35,73 \%$ belum mencapai target dan provinsi Jawa Barat sendiri sebanyak 38,23\% (Kementrian Kesehatan Republik Indonesia, 2018). Data profil kesehatan Kuningan Jawa Barat pada tahun 2013 capaian awal bayi yang mendapat ASI eksklusif sebesar 51,5\% dan target pada tahun 2018 sebesar 54\% (Dinas Kesehatan Kabupaten Kuningan, 2014).

Pencapaian ASI yang masih jauh dibawah target nasional, merupakan tanda bahwa kesadaran para ibu dalam memberikan ASI masih perlu ditingkatkan. Kendala ibu dalam menyusui ada dua faktor yaitu faktor internal kurangnya pengetahuan 
JOURNAL OF NURSING PRACTICE AND EDUCATION

VOL. 01 NO. 02, JUNI 2021

DOI: $10.34305 /$ jnpe.v1i2.265
Ciptaan disebarluaskan di bawah

$\underline{\text { Lisensi Creative Commons Atribusi- }}$

NonKomersial-BerbagiSerupa 4.0

Internasional. ibu tentang manajemen laktasi dan faktor eksternal ASI belum keluar pada hari-hari pertama sehingga ibu berpikir perlu tambah susu formula, ketidakmengertian ibu tentang kolostrum, banyak ibu yang masih beranggapan bahwa ASI ibu kurang gizi dan kualitasnya tidak baik (Baskoro, 2008). (Salmah, 2006) mengemukakan, ibu hamil perlu untuk meningkatkan pengetahuannya tentang pentingnya ASI. Adapun faktorfaktor yang mempengaruhi pengetahuan menurut (Mubarak, 2011) diantaranya, pendidikan, pekerjaan, umur, minat, pengalaman, kebudayaan lingkungan sekitar, dan informasi.

Rendahnya tingkat pemahaman tentang pentingnya ASI eksklusif karena kurangnya informasi dan pengetahuan yang dimiliki oleh para ibu (Prasetyono \& Hani'ah, 2009). Konseling dan persiapan pada masa kehamilan menyenai menyusui cenderung lebih meningkatkan tingkat pemberian ASI eksklusif, hal tersebut digunakan untuk promosi pemberian ASI eksklusif. Persiapan menyusui pada masa kehamilan juga merupakan hal yang penting karena dengan persiapan yang lebih baik, maka ibu lebih siap menyusui bayinya dan menunjang keberhasilan ASI eksklusif (Padmawati, 2013).

Berdasarkan studi pendahuluan yang dilakukan di Puskesmas Pasawahan bahwa terdapat 10 wilayah desa dengan presentasi yang memberikan ASI Eksklusif umur 0-6 bulan pada bulan Agustus 2017 seban7a $10,48 \%$ yang berarti dapat disimpulkan bahwa pemberian ASI Eksklusif masih rendah dari target pencapaian ASI eksklusif sebesar $80 \%$. Berdasarkan wawancara yang dilakukan peneliti di Desa Ciwiru (merupakan salah satu desa yang termasuk wilayah kerja Puskesmas Pasawahan) kepada 7 ibu hamil, menyatakan bahwa ibu tidak tahu tentang manajemen laktasi.

\section{Metode}

Penelitian ini menggunakan metode penelitian analitik yaitu jenis penelitian berdasarkan cara pandang (Badriah, 2012). Dalam konteks ini peneliti bermaksud mengetahui apakah terdapat hubungan karakteristik ibu hamil dengan pengetahuan manajemen laktasi.

\section{Populasi}


JOURNAL OF NURSING PRACTICE AND EDUCATION

VOL. 01 NO. 02, JUNI 2021

DOI: $10.34305 / J N P E . V 1 I 2.265$
Ciptaan disebarluaskan di bawah

$\underline{\text { Lisensi Creative Commons Atribusi- }}$

NonKomersial-BerbagiSerupa 4.0

Internasional.
Populasi dalam penelitian ini adalah ibu hamil sebanyak 346 di wilayah UPTD Puskesmas Pasawahan. instrumen yang digunakan adalah kuesioner yang diadopsi dari penelitian (Adelia, 2017). Hasil uji validitasnya adalah didapatkan $\mathrm{p}<$ taraf signifikan $(0,05)$ pada 33 item pertanyaan dan untuk uji reliabilitas, kuesioner ini reliabel untuk digunakan karena didapatkan $r$ instrumen ini lebih besar daripada $r$ tabel.

\section{Rancangan Analisis Data}

Analisis Univariat

Analisis univariat adalah analisis yang bertujuan mendeskripsikan karakteristik masing-masing variabel yang diteliti (Heriana, 2015). Pada umumnya analisis ini menghasilkan distribusi dan persentase dari tiap variable (Badriah, 2012).

Dilakukan dengan cara mencari hubungan antara variabel bebas karakteristik ibu hamil dengan variabel terikat tingkat pengetahuan tentang manajemen laktasi. Analisis bivariat dilakukan terhadap dua variabel yang diduga berhubungan satu sama lain, dapat dalam kedudukan yang silang pendekatan cross-sectional (Badriah, 2012). Uji statistik yang digunakan adalah Chisquare. Uji Chi-square adalah salah satu uji statistik non-parametrik yang cukup sering digunakan dalam penelitian yang menggunakan dua variabel, yang dimana skala data kedua variabel adalah ordinal.

Menurut Heriana (2015), jika p value $<\alpha$, dan $\mathrm{H}_{0}$ diterima, maka data sampel mendukung adanya perbedaan yang bermakna (signifikan) dan jika $\mathrm{p}$ value $<\alpha$, dan $\mathrm{H}_{0}$ diterima maka data sampel tidak mendukung adanya perbedaan yang bermakna (signifikan).

\section{Hasil}

Analisis Univariat

Tabel 5.1 Distribusi Frekuensi Pendidikan, Umur, Status Pekerjaan, dan Paritas Ibu Hamil di Wilayah Kerja UPTD Puskesmas Pasawahan

\begin{tabular}{ccc}
\hline Umur Frekuensi (F) & \multicolumn{2}{c}{ Persentase (\%) } \\
$<20$ tahun & 10 & $11 \%$ \\
20-35 tahun & 68 & $74,7 \%$ \\
$>35$ tahun & 13 & $14,3 \%$ \\
Total 91 & \multicolumn{2}{c}{$100 \%$} \\
\hline
\end{tabular}


JoURNAL OF NURSING PRACTICE AND EDUCATION

VOL. 01 NO. 02, JUNI 2021

DOI: $10.34305 /$ jnpe.v1i2.265
Ciptaan disebarluaskan di bawah Lisensi Creative Commons AtribusiNonKomersial-BerbagiSerupa 4.0 Internasional.

\begin{tabular}{ccc}
\hline Pendidikan & Frekuensi (F) & Persentase (\%) \\
Dasar & 37 & $40,7 \%$ \\
Menengah & 43 & $47,3 \%$ \\
Tinggi & 11 & $12,1 \%$ \\
Total & 91 & $100 \%$ \\
Status Pekerjaan & Frekuensi (F) & Persentase (\%) \\
Tidak Bekerja & 59 & $64,8 \%$ \\
Bekerja & 32 & $35,2 \%$ \\
Total & 91 & $100 \%$ \\
Paritas & Frekuensi (F) & Persentase (\%) \\
Primipara & 25 & $27,5 \%$ \\
Multipara & 57 & $62,6 \%$ \\
Grandemultipara & 9 & $9,9 \%$ \\
Total & 91 & $100 \%$
\end{tabular}

Berdasarkan tabel 5.1 di atas dapat diketahui bahwa dari 91 responden, sebagian besar memiliki umur 20-35 tahun sebanyak 68 responden $(74,7 \%)$, didominasi oleh pendidikan menengah sebanyak 43 responden $(47,3 \%)$, memiliki status pekerjaan tidak bekerja sebanyak 59 responden $(64,8 \%)$, dan sebagian besar paritas multipara sebanyak 57 responden $(62,2 \%)$.

Tabel 5.2 Distribusi Frekuensi Tingkat Pengetahuan Tentang Manajemen Laktasi di Wilayah Kerja UPTD Puskesmas

\begin{tabular}{ccc}
\hline Tingkat Pengetahuan Tentang Manajemen & Frekuensi (F) & Persentase (\%) \\
Laktasi & 16 & $17.6 \%$ \\
Baik $(76 \%-100 \%)$ & 52 & $57,1 \%$ \\
Cukup $(56 \%-75 \%)$ & 23 & $25,3 \%$ \\
Kurang $<56 \%$ & 91 & $100 \%$ \\
Total & & \\
\hline
\end{tabular}

Sumber : Hasil Penelitian Tahun 2019 
JOURNAL OF NURSING PRACTICE AND EDUCATION

VOL. 01 NO. 02, JUNI 2021

DOI: $10.34305 / J N P E . V 1 I 2.265$
Ciptaan disebarluaskan di bawah

$\underline{\text { Lisensi Creative Commons Atribusi- }}$

NonKomersial-BerbagiSerupa 4.0

Internasional.
Berdasarkan tabel 5.2 di atas dapat diketahui bahwa dari 91 responden, sebagian besar responden berpengetahuan cukup tentang manajemen laktasi sebanyak 52 responden $(57,1 \%)$.

Analisis Bivariat

Tabel 5.3 Hubungan antara Umur Ibu Hamil dengan Tingkat Pengetahuan Tentang Manajemen Laktasi di Wilayah Kerja UPTD Puskesmas Pasawahan

\begin{tabular}{|c|c|c|c|c|c|c|c|c|c|}
\hline \multirow{3}{*}{ Umur } & \multicolumn{6}{|c|}{ Tingkat Pengetahuan Tentang Manajemen laktasi } & \multicolumn{2}{|c|}{ Total } & \multirow{3}{*}{ Nilai $p$} \\
\hline & \multicolumn{2}{|c|}{ Baik } & \multicolumn{2}{|c|}{ Cukup } & \multicolumn{2}{|c|}{ Kurang } & & & \\
\hline & $\mathbf{F}$ & $\%$ & $\mathbf{F}$ & $\%$ & $\mathbf{F}$ & $\%$ & $\mathbf{N}$ & $\%$ & \\
\hline $\begin{array}{l}<20 \\
\text { tahun }\end{array}$ & 2 & 20 & 3 & 30 & 5 & 50 & 10 & 100 & \\
\hline $\begin{array}{l}20-35 \\
\text { tahun }\end{array}$ & 11 & 16,2 & 40 & 58,8 & 17 & 25 & 68 & 100 & $\mathbf{0 , 1 9 9}$ \\
\hline $\begin{array}{c}>35 \\
\text { tahun }\end{array}$ & 3 & 23,1 & 9 & 69,2 & 1 & 7,7 & 13 & 100 & \\
\hline
\end{tabular}

Sumber : Hasil Penelitian Tahun 2019

Berdasarkan tabel 5.3 diatas menunjukan bahwa dari 10 responden dengan umur $<20$ tahun sebagian besar berpengetahuan kurang tentang manajemen laktasi sebanyak 5 responden (50\%), dari 68 responden dengan umur 20-35 tahun sebagian besar berpengetahuan cukup sebanyak 40 responden $(58,8 \%)$, dan dari 13 responden dengan umur $>35$ tahun sebagian besar berpengetahuan cukup sebanyak 9 responden $(69,2 \%)$. Berdasarkan hasil uji statistik dengan menggunakan uji Chi Square dengan menggunakan program SPSS diperoleh nilai $\mathrm{p}$ yaitu 0,199 dengan tingkat kemaknaan $\alpha=0,05$ maka dapat disimpulkan bahwa nilai p sebesar 0,199> 0,05, sehingga tidak terdapat hubungan antara umur ibu hamil dengan pengetahuan manajemen laktasi di wilayah kerja UPTD Puskesmas Pasawahan.

\section{Tabel 5.4 Hubungan antara Pendidikan Ibu Hamil dengan Tingkat Pengetahuan} tentang Manajemen Laktasi di Wilayah Kerja UPTD Puskesmas Pasawahan

\begin{tabular}{cccccccccccc}
\hline & \multicolumn{4}{c}{ Tingkat Pengetahuan Tentang Manajemen laktasi } & \multicolumn{2}{c}{ Total } & Nilai $\boldsymbol{p}$ \\
Pendidikan & \multicolumn{4}{c}{ Baik } & \multicolumn{2}{c}{ Cukup } & Kurang & & & \\
& F & \% & F & \% & F & \% & N & \% & \\
Dasar & 10 & 27 & 21 & 56,8 & 6 & 16,2 & 37 & 100 & \\
Menengah & 4 & 9,3 & 23 & 53,5 & 16 & 37,2 & 43 & 100 & $\mathbf{0 , 0 6 4}$ \\
Tinggi & 2 & 18,2 & 8 & 72,7 & 1 & 9,1 & 11 & 100 & \\
\hline
\end{tabular}


JOURNAL OF NURSING PRACTICE AND EDUCATION

VOL. 01 No. 02, JUNI 2021

DOI: $10.34305 /$ jnpe.v1i2.265
Ciptaan disebarluaskan di bawah

Lisensi Creative Commons Atribusi-

NonKomersial-BerbagiSerupa 4.0

Internasional.
Berdasarkan tabel 5.4 di atas menunjukan bahwa dari 37 responden dengan pendidikan dasar sebagian besar berpengetahuan cukup tentang manajemen laktasi sebanyak 21 responden $(56,8 \%)$, dari 43 responden dengan pendidikan menengah sebagian besar berpengetahuan cukup sebanyak 23 responden $(53,5 \%)$, dan dari 11 responden dengan pendidikan tinggi sebagian besar berpengetahuan cukup sebanyak 8 responden (72,2\%). Berdasarkan hasil uji statistik dengan menggunakan uji Chi Square dengan menggunakan program SPSS diperoleh nilai pyaitu 0,064 dengan tingkat kemaknaan $\alpha=0,05$ maka dapat disimpulkan bahwa nilai $\mathrm{p}$ sebesar 0,064 > 0,05 , sehingga tidak terdapat hubungan antara pendidikan ibu hamil dengan pengetahuan manajemen laktasi di wilayah kerja UPTD Puskesmas Pasawahan.

Tabel 5.5 Hubungan antara Status Pekerjaan Ibu Hamil dengan Tingkat Pengetahuan tentang Manajemen Laktasi di Wilayah Kerja UPTD Puskesmas Pasawahan

\begin{tabular}{ccccccccccc}
\hline $\begin{array}{c}\text { Status } \\
\text { Pekerjaan }\end{array}$ & \multicolumn{2}{c}{ Tingkat Pengetahuan Tentang Manajemen laktasi } & \multicolumn{2}{c}{ Total } & Nilai $\boldsymbol{p}$ \\
& Baik & F & Cukup & F & \% & F & \% & N & \% & \\
Tidak Bekerja & 13 & 22 & 31 & 52,5 & 15 & 25,4 & 59 & 100 & $\mathbf{0 , 2 8 5}$ \\
Bekerja & 3 & 9,4 & 21 & 65,6 & 8 & 25 & 32 & 100 & \\
\hline
\end{tabular}

Sumber : Hasil Penelitian Tahun 2019

Berdasarkan tabel 5.5 diatas menggunakan uji Chi Square dengan menunjukan bahwa dari 59 responden menggunakan program SPSS diperoleh nilai dengan status tidak bekerja sebagian besar p yaitu 0,285 tingkat kemaknaan $\alpha=0,05$ berpengetahuan cukup tentang manajemen maka dapat disimpulkan bahwa nilai $p$ laktasi sebanyak 31 responden $(52,5 \%)$, dan dari 32 responden dengan status bekerja sebagian besar berpengetahuan cukup sebesar 0,285>0,05, sehingga tidak terdapat hubungan antara pekerjaan ibu hamil dengan sebanyak 21 responden $(65,6,2 \%)$. pengetahuan ibu hamil tentang manajemen laktasi di wilayah kerja UPTD Puskesmas Berdasarkan hasil uji statistik dengan Pasawahan.

Tabel 5.6 Hubungan antara Paritas Ibu Hamil dengan Tingkat Pengetahuan tentang Manajemen Laktasi di Wilayah Kerja UPTD Puskesmas Pasawahan

\begin{tabular}{cccc}
\hline Paritas & Tingkat Pengetahuan Tentang Manajemen \\
laktasi & Total & Nilai $p$ \\
\hline
\end{tabular}


JOURNAL OF NURSING PRACTICE AND EDUCATION

VOL. 01 NO. 02, JUNI 2021

DOI: $10.34305 / J N P E . V 1 I 2.265$
Ciptaan disebarluaskan di bawah

Lisensi Creative Commons Atribusi-

NonKomersial-BerbagiSerupa 4.0

Internasional.

\begin{tabular}{cccccccccc}
\hline & \multicolumn{2}{c}{ Baik } & \multicolumn{1}{c}{ Cukup } & Kurang & & & \\
& F & $\mathbf{\%}$ & $\mathbf{F}$ & $\mathbf{\%}$ & $\mathbf{F}$ & $\mathbf{\%}$ & $\mathbf{N}$ & $\mathbf{\%}$ & \\
Primipara & 0 & 0 & 13 & 52 & 12 & 48 & 25 & 100 & \\
Multipara & 13 & 22,8 & 34 & 59,6 & 10 & 17,5 & 57 & 100 & $\mathbf{0 , 0 0 8}$ \\
Grandemultipara & 3 & 33,3 & 5 & 55,6 & 1 & 11,1 & 9 & 100 & \\
\hline
\end{tabular}

Sumber : Hasil Penelitian Tahun 2019

Berdasarkan tabel 5.6 diatas menunjukan bahwa dari 25 responden dengan paritas primipara sebagian besar berpengetahuan cukup tentang manajemen laktasi sebanyak 13 responden (52\%), dari 57 responden dengan paritas multipara sebagian besar berpengetahuan cukup sebanyak 34 responden $(59,6 \%)$, dan dari 9 responden dengan paritas grandemultipara sebagian besar berpengetahuan cukup sebanyak 5 responden $(55,6 \%)$. Berdasarkan hasil uji statistik dengan menggunakan uji Chi Square dengan menggunakan program SPSS diperoleh nilai $\mathrm{p}$ yaitu 0,008 dengan tingkat kemaknaan $\alpha=0,05$ maka dapat disimpulkan bahwa nilai p sebesar $0,008<$ 0,05, sehingga terdapat hubungan antara paritas ibu hamil dengan pengetahuan manajemen laktasi di wilayah kerja UPTD Puskesmas Pasawahan.

\section{Pembahasan}

Analisi Univariat
Berdasarkan hasil analisis diperoleh dari 91 ibu hamil sebagian berumur 20-35 tahun sebanyak 74,7\% . Hal ini sesuai dengan pendapat Prawirohardjo (2016) yang mengatakan umur sangat berpengaruh terhadap proses reproduksi, umur dianggap optimal untuk kehamilan dan persalinan adalah 20-35 tahun, sedangkan umur lebih dari 35 tahun dan kurang dari 20 tahun yang dianggap berbahaya.

Berdasarkan hasil peneliti bahwa sebagian besar responden berumur 20-35 tahun yang dikatakan umur dengan reproduksi sehat, dimana kondisi fisik dan mentalnya dalam keadaan baik. Pada masa ini responden sudah siap menjadi ibu, siap menerima tanggung jawab dalam mengurus bayinya sehingga ibu akan memberikan yang terbaik untuk bayinya. Salah satu cara pada ibu dengan umur berisiko sebaiknya mengikuti $\mathrm{KB}$ agar dapat mengatur kehamilannya maupun mengakhiri kehamilan. 
JOURNAL OF NURSING PRACTICE AND EDUCATION

VOL. 01 NO. 02, JUNI 2021

DOI: $10.34305 /$ jnpe.v1i2.265
Ciptaan disebarluaskan di bawah

Lisensi Creative Commons Atribusi-

NonKomersial-BerbagiSerupa 4.0

Internasional.
Berdasarkan hasil analisis diperoleh dari $91 \mathrm{ibu}$ hamil sebagian dengan pendidikan menengah sebanyak $47,3 \%$. Hal ini sesuai yang dinyatakan oleh Wawan \& Dewi (2010) bahwa ibu-ibu yang mempunyai tingkat pendidikan yang lebih tinggi, pada umumnya lebih terbuka menerima perubahan atau hal-hal baru guna pemeliharaan kesehatannya.

Berdasarkan hasil pengamatan peneliti, responden sebagian besar dengan pendidikan menengah dapat mempengaruhi pengetahuan dan motivasi ibu, sehingga ibu yang mempunyai pendidikan menengah cenderung mudah menerima informasi seperti yang telah disebutkan oleh teori diatas. Pendidikan rendah mempunyai dampak terhadap kesehatan, pemerintah sudah mengeluarkan program yang baik bagi masyarakat yaitu wajib belajar 9 tahun, alangkah baiknya jika dilanjutkan program tersebut menjadi pendidikan menengah 12 tahun, di samping itu sebaiknya bagi masyarakat sendiri mempunyai niat dan harapan yang lebih baik dari sebelumnya dengan motivasi yang tinggi untuk menambah pengetahuan baik dengan mengikuti pendidikan formal dan non formal seperti pelatihan karena dengan pendidikan pasti akan membuat seseorang berkeinginan untuk ingin tahu, untuk mencari pengalaman baru dan untuk mengorganisasikan pengalaman yang di dapat sehingga informasi yang diterima akan menjadi pengetahuan.

Berdasarkan hasil analisis diperoleh dari 91 ibu hamil sebagian besar tidak bekerja sebanyak $(64,8 \%)$. Hal tersebut sesuai dengan pendapat Notoatmodjo (2007) menyatakan pekerjaan itu memiliki peranan penting dalam menentukan kualitas hidup manusia, pekerjaan juga membatasi kesenjangan antara informasi kesehatan dan praktek yang membuat motivasi seseorang untuk memperoleh informasi dan berbuat sesuatu untuk menghindari suatu masalah dalam kesehatan.

Berdasarkan hasil pengamatan peneliti, sebagian besar responden tidak bekerja, dikarenakan ibu yang tidak bekerja otomatis tidak mempunyai penghasilan yang dihasilkan oleh ibu, meskipun demikian ternyata ibu yang tidak bekerja mempunyai dampak positif bagi keluarga, hal ini sesuai dengan kodratnya bahwa seorang ibu yang baik adalah ibu yang bisa mendidik, 
JOURNAL OF NURSING PRACTICE AND EDUCATION

VOL. 01 NO. 02, JUNI 2021

DOI: $10.34305 / J N P E . V 1 I 2.265$
Ciptaan disebarluaskan di bawah

Lisensi Creative Commons Atribusi-

NonKomersial-BerbagiSerupa 4.0

Internasional. mengasuh dan mengurus keluarganya dengan benar sehingga akan tercipta keluarga yang harmonis, pada saat mempunyai bayi maka ibu dapat melakukan manajemen laktasi yang baik, disamping itu ibu dapat mengetahui pertumbuhan dan perkembangan bayi dengan baik seperti yang telah disebutkan oleh teori diatas. Salah satu cara pada ibu yang bekerja, meskipun kondisi ibu bekerja, sebaiknya ibu mempersiapkan ASI terlebih dahulu untuk bayinya dengan cara memompa ASI.

Berdasarkan hasil analisis diperoleh dari 91 ibu hamil sebagian besar dengan multipara sebanyak 62,6\%. Banyak ibu bersalin dalam melahirkan dapat dikaitkan dengan pengetahuan dan pengalaman ibu bersalin tentang kehamilan, persalinan dan merawat anak sehingga ibu yang sudah pernah bersalin akan mempunyai pengalaman. Pengetahuan dan pengalaman yang baik akan mempengaruhi jarak kehamilan, jumlah kelahiran ibu dalam kehamilan.

Berdasarkan hasil pengamatan peneliti, responden sebagian besar dengan multipara, ibu yang sudah memiliki banyak paritas diharapkan akan dapat merubah pengetahuan,sikap dan perilaku ibu dan keluarganya untuk hidup lebih sehat. Paritas yang dimaksud dalam penelitian ini disebut juga pengalaman ibu melahirkan dan mempunyai anak. Pengalaman sendiri adalah sesuatu yang dialami seseorang akan menambah pengetahuan tentang sesuatu yang bersifat non formal. Pengalaman juga merupakan salah satu faktor yang mempengaruhi pengetahuan seseorang. Pengalaman yang banyak yang diperoleh seseorang, maka orang tersebut akan mempunyai pengetahuan yang lebih luas karena seseorang yang sudah pernah mengalami suatu kejadian maka orang tersebut bisa mengalami kejadian yang sama dia akan mengingat dan sudah tahu bagaimana dan apa yang harus dilakukannya.

Berdasarkan hasil analisis diperoleh dari 91 ibu hamil sebagian responden berpengetahuan cukup Hal ini kemungkinan disebabkan karena dipengaruhi oleh faktor umur karena mayoritas ibu menyusui di wilayah kerja UPTD Puskesmas Pasawahan mayoritas berumur 20 - 35 tahun. Pengetahuan responden salah satunya juga dipengaruhi oleh faktor pendidikan yaitu 
JOURNAL OF NURSING PRACTICE AND EDUCATION

VOL. 01 NO. 02, JUNI 2021

DOI: $10.34305 /$ jnpe.v1i2.265
Ciptaan disebarluaskan di bawah

Lisensi Creative Commons Atribusi-

NonKomersial-BerbagiSerupa 4.0

Internasional. makin tinggi tingkat pendidikan seseorang, maka makin mudah menerima informasi sehingga makin banyak pula pengetahuan yang dimiliki. Ibu Hamil di wilayah kerja UPTD Puskesmas Pasawahan mayoritas berpendidikan menengah. Serta pengetahuan responden dipengaruhi juga oleh faktor pekerjaan dan paritas yang diperoleh melalui pengalaman sebelumnya dan juga informasi dari media elektronik (televisi dan radio), media cetak (koran, majalah, artikel) dan penyuluhan tenaga kesehatan.

Menurut Notoatmodjo (2007), faktor yang mempengaruhi pengetahuan adalah umur dimana semakin tua umur seseorang ingatannya semakin berkurang, sehingga sulit menerima informasi yang diberikan, sebaliknya semakin muda umur seseorang maka akan mudah menerima informasi yang didapat dan akan lebih tertarik untuk mengetahui sesuatu hal. Faktor pendidikan juga mempengaruhi pengetahuan, karena pendidikan merupakan upaya untuk memberikan pengetahuan sehingga terjadi perubahan perilaku positif seseorang yang meningkat. Menurut Notoatmodjo (2007), faktor yang mempengaruhi pengetahuan yaitu informasi. Informasi yang diperoleh melalui kenyataan (melihat dan mendengar sendiri), serta melalui media surat kabar, radio, tv dapat menambah pengetahuan lebih luas.

\section{Analisis Bivariat}

Berdasarkan hasil uji statistik menggunakan uji Chi Square program SPSS di nilai $p$ yaitu 0,199 tingkat kemaknaan $\alpha=$ 0,05 maka dapat disimpulkan bahwa, nilai $\mathrm{p}$ sebesar 0,199>0,05, sehingga tidak ada hubungan antara umur ibu hamil dengan tingkat pengetahuan manajemen laktasi di wilayah kerja UPTD Puskesmas Pasawahan.

Penelitian ini tidak sesuai oleh hasil penelitian Simadasari (2007), dengan judul penelitian yang menyatakan bahwa pengetahuan ibu tidak dipengaruhi umur. Ibu yang berumur lebih tua belum tentu memiliki pengetahuan yang baik mengenai ASI dan Manajemen Laktasi.

Berdasarkan pengamatan peneliti, responden sebagian besar berpengetahuan cukup, hal ini disebabkan oleh beberapa faktor diantaranya umur ibu hamil, usia rentang 20-35 tahun di daerah penelitian mayoritas adalah keluarga baru dan sangat 
JOURNAL OF NURSING PRACTICE AND EDUCATION

VOL. 01 NO. 02, JUNI 2021

DOI: $\underline{10.34305 / J N P E . V 1 I 2.265}$

menginginkan agar anaknya kelak sehat sehingga informasi yang diberikan oleh tenaga kesehatan sangat dibutuhkan. Umur ibu yang kurang dari 20 tahun, biasanya pada usia tersebut emosinya belum stabil sehingga kondisi kejiwaan belum siap untuk mempunyai anak. Hal ini sesuai pendapat Adelia (2017) yang menyatakan bahwa persiapan psikologis ibu sangat menentukan keberhasilan menyusui.

Selain itu, kurangnya motivasi ibu untuk mengikuti posyandu disebabkan kurangnya informasi mengenai posyandu yang didalamnya terdapat kelas ibu hamil, sehingga responden menganggap bahwa kelas ibu hamil tidak bermanfaat bagi kesehatan selama kehamilan. Menurut Dapartemen Kesehatan Republik Indonesia (2009), kelas ibu hamil mempunyai banyak manfaat seperti ibu dapat mengetahui masalah masalah selama masa kehamilan, perawatan kehamilan, persalinan, perawatan masa nifas, perawatan bayi baru lahir, mitos selama kehamilan, penyakit menular dan tidak menular yang bisa mengganggu kehamilan (Dapartemen Kesehatan Republik Indonesia, 2009).
Ciptaan disebarluaskan di bawah $\underline{\text { Lisensi Creative Commons Atribusi- }}$ NonKomersial-BerbagiSerupa 4.0 Internasional.
Berdasarkan hasil uji statistik menggunakan uji Chi Square dengan program SPSS di nilai p yaitu 0,064 tingkat kemaknaan $\alpha=0,05$ maka dapat disimpulkan bahwa, nilai p sebesar 0,064> 0,05 , sehingga tidak ada hubungan antara pendidikan ibu hamil dengan tingkat pengetahuan manajemen laktasi di wilayah kerja UPTD Puskesmas Pasawahan.

Hal ini sejalan dengan penelitian Sartono \& Utaminingrum (2012) yang menyatakan bahwa tidak ada hubungan yang bermakna antara pendidikan ibu dengan praktik pemberian ASI eksklusif $(\mathrm{p}=1,000)$. Namun dalam penelitian ini tidak sesuai dengan Mubarak (2011) yang menyatakan bahwa semakin tinggi tingkat pendidikan seseorang maka akan semakin mudah menerima informasi dan nilai-nilai yang baru, sebaliknya semakin rendah pendidikan seseorang maka akan menghambat perkembangan seseorang terhadap penerimaan, informasi dan nilai-nilai yang baru.

Berdasarkan hasil uji statistik menggunakan uji Chi Square dengan program SPSS di nilai p yaitu 0,285 dengan tingkat kemaknaan $\alpha=0,05$ maka dapat 
JOURNAL OF NURSING PRACTICE AND EDUCATION

VOL. 01 NO. 02, JUNI 2021

DOI: $10.34305 /$ jnpe.v1i2.265
Ciptaan disebarluaskan di bawah

Lisensi Creative Commons Atribusi-

NonKomersial-BerbagiSerupa 4.0

Internasional. disimpulkan bahwa, nilai p sebesar 0,285> 0,05, sehingga tidak ada hubungan antara status pekerjaan ibu hamil dengan tingkat pengetahuan manajemen laktasi di wilayah kerja UPTD Puskesmas Pasawahan.

Sejalan dengan penelitian yang dilakukan oleh Anggrita (2009) yang menyatakan bahwa diperoleh nilai $\mathrm{p} \geq 0,05$ $(\mathrm{p}=0,955)$ yang berarti tidak dijumpai hubungan yang bermakna secara statistik antara pekerjaan ibu menyusui dengan pemberian Manajemen Laktasi. Sejalan pula dengan penelitian Sulistyoningsih (2011) yang menyatakan dalam penelitiannya tidak terdapat hubungan yang signifikan antara pekerjaan dengan perilaku Manajemen Laktasi. Pada ibu bekerja, penyebab kurangnya cakupan pemberian ASI eksklusif adalah singkatnya masa cuti hamil atau melahirkan yaitu rata-rata hanya tiga bulan, keterbatasan waktu atau kesibukan kerja dan ketersediaan fasilitas untuk menyusui di tempat kerja menyebabkan penggunaan botol atau susu formula diberikan lebih dini (Kementrian Kesehatan Republik Indonesia, 2018).

Namun demikian, Swandari (2013) menyatakan bahwa semakin banyak wanita yang bekerja maka akan semakin mempengaruhi upaya ibu dalam menyusui bayi. Berdasarkan hasil penelitian menunjukkan bahwa ibu yang tidak bekerja cenderung baik manajemen laktasinya sebanyak 40 responden $(75,5 \%)$ dibandingkan dengan ibu yang bekerja, yaitu sebanyak 24 responden $(68,6 \%)$ yang mempunyai manajemen laktasi dalam kategori baik. Hal ini disebabkan pada ibu bekerja hanya melakukan manajemen laktasi sesuai dengan kemampuannya, karena waktu untuk menyusui bayi terhambat karena pekerjaannya, sedangkan pada ibu yang tidak bekerja, mereka merasa selalu bisa memberikan ASI ketika bayi membutuhkannya. Demikian pula dalam melakukan manajemen laktasi, ibu yang tidak bekerja mempunyai waktu yang lebih banyak untuk bayinya dibandingkan dengan ibu yang bekerja.

Namun, penelitian ini tidak sejalan dengan penelitian yang dilakukan oleh Abdullah \& Ayubi (2013), yaitu terdapat hubungan signifikan antara keterpaparan informasi dengan pengetahuan responden. Semakin banyak mendapatkan paparan tentang Manajemen Laktasi, maka akan 
JOURNAL OF NURSING PRACTICE AND EDUCATION

VOL. 01 NO. 02, JUNI 2021

DOI: $10.34305 / J N P E . V 1 I 2.265$
Ciptaan disebarluaskan di bawah

$\underline{\text { Lisensi Creative Commons Atribusi- }}$

NonKomersial-BerbagiSerupa 4.0

Internasional. semakin baik pengetahuannya tentang ASI eksklusif. Sumber informasi tersebut bisa didapatkan dari internet, buku, dan media massa. Adapun majalah merupakan media sumber informasi yang paling banyak diakses oleh ibu yang bekerja.

Utamanya pada ibu yang bekerja terdapat beberapa hal yang dapat menghambat keberhasilan dalam menyusui, diantaranya karena ingin lebih praktis, mudah dan hemat waktu, maka hal tersebut biasanya susu formula dijadikan sebagai alternative (Okawary \& Sugiyanto, 2015). Selain itu, faktor kelelahan akibat bekerja dan kurangnya dukungan dari tempat bekerja juga berdampak terhadap hal ini. Tidak adanya fasilitas ruangan untuk laktasi serta pendeknya masa cuti kerja juga dapat mempengaruhi keberhasilan ASI eksklusif (Ikatan Dokter Anak Indonesia, 2013).

Berdasarkan hasil uji statistik menggunakan uji Chi Square dengan program SPSS di nilai p yaitu 0,008 tingkat kemaknaan $\alpha=0,05$ maka dapat disimpulkan bahwa, nilai p sebesar 0,008< 0,05, sehingga terdapat hubungan antara paritas ibu hamil dengan tingkat pengetahuan manajemen laktasi di wilayah kerja UPTD Puskesmas Pasawahan.

Hal ini didukung dengan penelitian Lestari \& Nawangsih (2013) yaitu pemberian ASI eksklusif lebih banyak ditemukan pada ibu multipara dibandingkan primipara. Mabud et al., (2014) mengayakan bahwa ibu multipara erat kaitannya dengan adanya pengetahuan yang didapat dari pengalaman menyusui sebelumnya. Ketika seorang ibu sebelumnya sudah pernah mengalami menyusui, maka hal itu akan menjadi pengetahuan baginya ketika menyusui kembali di masa selanjutnya. Ketika sudah belajar dari pengalaman sebelumnya, maka dimungkinkan bahwa ibu dapat mengatasi permasalahan yang mungkin saja dihadapi.

\section{Kesimpulan}

Berdasarkan hasil penelitian tentang hubungan antara karakteristik ibu hamil dengan tingkat pengetahuan manajemen laktasi di wilayah kerja UPTD Puskesmas Pasawahan Tahun 2019 maka penulis membuat kesimpulan sebagai berikut:

Sebagian ibu hamil di wilayah kerja UPTD Puskesmas Pasawahan memiliki 
JOURNAL OF NURSING PRACTICE AND EDUCATION

VOL. 01 NO. 02, JUNI 2021

DOI: $10.34305 /$ jnpe.v1i2.265
Ciptaan disebarluaskan di bawah

$\underline{\text { Lisensi Creative Commons Atribusi- }}$

NonKomersial-BerbagiSerupa 4.0

Internasional. umur 20-35 tahun sebanyak 68 responden $74,7 \%$, pendidikan menengah sebanyak 43 responden $47,3 \%$, tidak bekerja sebanyak 59 responden $64,8 \%$, dan paritas multipara sebanyak 57 responden $62,6 \%$.

Sebagian ibu hamil di wilayah kerja UPTD Puskesmas Pasawahan berpengetahuan cukup tentang manajemen laktasi sebanyak 52 responden $57,1 \%$.

Tidak terdapat hubungan antara umur ibu hamil dengan tingkat pengetahuan tentang manajemen laktasi di wilayah kerja UPTD Puskesmas Pasawahan dengan nilai $p$ $=0,199$.

Tidak terdapat hubungan antara pendidikan ibu hamil dengan tingkat pengetahuan tentang manajemen laktasi di wilayah kerja UPTD Puskesmas Pasawahan Tahun 2019 dengan nilai $\mathrm{p}=0,064$.

Tidak terdapat hubungan antara pekerjaan ibu hamil dengan tingkat pengetahuan tentang manajemen laktasi di wilayah kerja UPTD Puskesmas Pasawahan dengan nilai $\mathrm{p}=0,285$.

Terdapat hubungan antara paritas ibu hamil dengan tingkat pengetahuan tentang manajemen laktasi di wilayah kerja UPTD
Puskesmas Pasawahan dengan nilai $\mathrm{p}=$ 0,008 .

\section{Saran}

Bagi ibu hamil

Meningkatkan pengetahuan tentang manajemen laktasi melalui rajin mengikuti posyandu, aktif bertanya pada petugas kesehatan khususnya mengenai manajemen laktasi, dan mencari tahu lewat membaca baik pada poster maupun media lainnya agar ibu mampu memberikan yang terbaik untuk bayinya nanti sehingga dapat menyusui secara ASI Eksklusif dengan manajemen laktasi yang baik.

\section{Bagi Tenaga Kesehatan}

Diharapkan lebih intensif melakukan penyuluhan dan konseling oleh petugas promosi kesehatan dengan membuat kelas laktasi, perlu diadakan pemberian apresiasi bagi para ibu hamil yang rutin hadir dalam jam posyandu.

\section{Daftar Pustaka}

Abdullah, G. I., \& Ayubi, D. (2013). Determinan Perilaku Pemberian Air Susu Ibu Eksklusif pada Ibu Pekerja. Kesmas: Jurnal Kesehatan Masyarakat Nasional (National Public Health Journal), 7(7), 298-303. 
JOURNAL OF NURSING PRACTICE AND EDUCATION

VOL. 01 NO. 02, JUNI 2021

DOI: $10.34305 / J N P E . V 1 I 2.265$

Adelia, W. S. (2017). Hubungan Status Pekerjaan dan Pengetahuan tentang Manajemen Laktasi terhadap Pemberian Asi Eksklusif di Wilayah Kerja Puskesmas Tegalrejo Kota Yogyakarta.

Anggrita, K. (2009). Hubungan Karakteristik Ibu Menyusui terhadap Pemberian ASI Eksklusif di Wilayah Kerja Puskesmas Medan Amplas Tahun 2009. Tersedia Dari URL: HYPERLINK Http://Www. Koleksiskripsi. Com/2011/05/Hbung an-Karakteristik-Ibu-Menyusui. Html.

Badriah, D. L. (2012). Metodologi Penelitian Ilmu-Ilmu Kesehatan. Bandung: Multazam.

Baskoro, A. (2008). ASI Panduan Praktis Ibu Menyusui. Yogyakarta: Banyu Media, 1-24.

Bidan Indonesia. (2018). Kebidanan: Teori dan Asuhan. Jakarta: EGC.

Dapartemen Kesehatan Republik Indonesia. (2009). Pedoman Pelaksanaan Program Rumah Sakit Sayang Ibu dan Bayi.

Dinas Kesehatan Kabupaten Kuningan. (2014). Rencana Strategis Dinas Kesehatan Kabupaten Kuningan Tahun 2014-2018. Dinas Kesehatan Kabupaten Kuningan. https://dinkes.kuningankab.go.id/direkt ori-data/renstra-dinkes-2014-2018

Heriana, C. (2015). Manajemen Pengolahan Data Kesehatan.

Ikatan Dokter Anak Indonesia. (2013).
Ciptaan disebarluaskan di bawah $\underline{\text { Lisensi Creative Commons Atribusi- }}$ NonKomersial-BerbagiSerupa 4.0 Internasional. (i)(2)

Sukses Menyusui Saat Bekerja. Ikatan Dokter Anak Indonesia. https://www.idai.or.id/artikel/klinik/asi /sukses-menyusui-saat-bekerja-2

Kementrian Kesehatan Republik Indonesia. (2018). Profil Kesehatan Indonesia Tahun 2017. Kementrian Kesehatan Republik Indonesia.

Lestari, A. R., \& Nawangsih, U. H. E. (2013). Hubungan Tingkat Pengetahuan tentang ASI Eksklusif dan Paritas Ibu Menyusui dengan Pemberian ASI Eksklusif di Puskesmas Sewon II Bantul Tahun 2013. STIKES'Aisyiyah Yogyakarta.

Mabud, N. H., Mandang, J., \& Mamuaya, T. (2014). Hubungan Pengetahuan, Pendidikan, Paritas dengan Pemberian ASI Eksklusif di Puskesmas Bahu Kecamatan Malalayang Kota Manado. JIDAN (Jurnal Ilmiah Bidan), 2(2), 5156.

Mubarak, W. I. (2011). Promosi Kesehatan untuk Kebidanan.

Notoatmodjo, S. (2007). Promosi Kesehatan \& Ilmu Perilaku.

Okawary, O., \& Sugiyanto, S. (2015). Hubungan Status Pekerjaan Ibu dengan Pemberian Asi Eksklusif di Wilayah Kerja Puskesmas Sayegan Sleman Yogyakarta. STIKES'Aisyiyah Yogyakarta.

Padmawati, I. (2013). Manajemen Laktasi.

Prasetyono, D. S., \& Hani'ah, M. (2009). 
JOURNAL OF NURSING PRACTICE AND EDUCATION

VOL. 01 NO. 02, JUNI 2021

DOI: $10.34305 /$ jnpe.v1i2.265
Ciptaan disebarluaskan di bawah Lisensi Creative Commons AtribusiNonKomersial-BerbagiSerupa 4.0 Internasional. (i)(2)
Buku Pintar ASI Ekslusif Pengenalan, Praktik, dan Kemanfaatankemanfaatannya. Jogjakarta Diva Press 2009.

Prawirohardjo, S. (2016). Ilmu Kebidanan. Yayasan Bina Pustaka.

Salmah. (2006). Asuhan Kebidanan Antenatal. EGC.

Sartono, A., \& Utaminingrum, H. (2012). Hubungan Pengetahuan Ibu, Pendidikan Ibu dan Dukungan Suami dengan Praktek Pemberian Asi Eksklusif di Kelurahan Muktiharjo Kidul Kecamatan Telogosari Kota Semarang. Jurnal Gizi, 1(1).

Simadasari. (2007). Karakteristik dan Perilaku Ibu yang Memberikan ASI Esklusif dan Manajemen Laktasi di Wilayah Kerja Puskesmas Kabanjahe. Jurnal Kesehatan.

Sulistyoningsih, H. (2011). Gizi untuk Kesehatan Ibu dan Anak.
Swandari, S. (2013). Manajemen Laktasi Bagi Ibu Bekerja.

Tarigan, I. U., \& Aryastami, N. K. (2012). Pengetahuan, Sikap dan Perilaku Ibu Bayi Terhadap Pemberian ASI Eksklusif. Buletin Penelitian Sistem Kesehatan, 15(4), 21366.

Unicef. (2015). Breastfeeding. Unicef. https://sites.unicef.org/nutrition/index_ 24824.html

Wawan, A., \& Dewi, M. (2010). Teori dan Pengukuran Pengetahuan, Sikap dan Perilaku Manusia. Yogyakarta: Nuha Medika, 11-18.

WHO. (2013). Breastfeeding: Only 1 in 5 contries fully implement WHO's infant formula Code. World Health Organization. http://www.emro.who.int/pressreleases/2013/world-breastfeedingweek-2013.html 